\title{
A Qualitative Case Study into Exploring the Learning Styles and Learning Strategies of Non English Major Vietnamese College Students
}

\author{
Truong Thi Nhu Ngoc ${ }^{1}$, Arshad Abd Samad ${ }^{2, *}$ \\ ${ }^{1}$ Faculty of Foreign Language, Van Lang University, Vietnam \\ ${ }^{2}$ Department of Language and Humanities Education, Faculty of Educational Studies, Universiti Putra Malaysia, Malaysia
}

Received October 27, 2019; Revised December 2, 2019; Accepted December 24, 2019

Copyright $\subseteq 2020$ by authors, all rights reserved. Authors agree that this article remains permanently open access under the terms of the Creative Commons Attribution License 4.0 International License

\begin{abstract}
Learning styles and learning strategies have long been studied because they can influence learners' success and promote learners' autonomy, particularly in language learning. However, most studies in this area are carried out in international contexts rather than locally. Thus, many false assumptions have been made about Asian learning styles in general and Vietnamese learners in particular, i.e. they are passive and group-oriented learners, and they tend to learn by rote and memorising knowledge. The case study represents an attempt to find out if first-year non-English majored collegiate learners in Vietnam are passive or active. The significant findings from semi-structured interviews with two first-year non-English-majored Vietnamese college students indicate that Vietnamese college students are not passive and rote learners and the reasons for their reticence in class relate to their learning styles and the nature of the questions asked by their teacher. Furthermore, whether Vietnamese college students are group-oriented or not is not clearly proven from the finding. It may also depend on the students' personality and how they view learning in a group. For that reason, further research is necessary. As regards learning strategies, it is not always the rote learning approach that the students employ. They only resort to it for fear of having lower marks in the exam. They learn with understanding and use other strategies to help them memorise the knowledge.
\end{abstract}

Keywords Passive Learners, Active Learners, Style, Strategies

\section{Introduction}

The past fifty years have witnessed a considerable number of methodologies springing up and claiming to be effective practices to boost students' second language learning capabilities. These methods and approaches are mostly determined by educators and teachers, which can lead to the fact that what students acquire is a far cry from what they are taught. For that reason, a more learner-centred approach will likely bring in expected results. However, how can teachers understand their students well enough in addition to knowing their needs? To deploy suitable classroom activities effectively, it is vital to examine students' learning styles and strategies. Unfortunately, sometimes, teachers can have misconceptions or overgeneralizations about their students' styles and strategies due to being susceptible to what they read and misjudging what they see. In other words, a conscientious teacher should be not only sensitive to dissimilarities among their students but also able to avoid stereotyping them. It is evident that the majority of second language learning research about Asian learners is carried out in the English-speaking countries and thus an inaccurate picture of Asian learners in general and Vietnamese learners, in particular, can be generated (Hong-Nam \& Leavell, 2006; Park, 1997, 2002; Young, 2018).

In Vietnam, most students start to learn English at lower secondary schools, and English has become an obligatory subject throughout a learner's educational journey. When students enroll in university, they also continue to make great efforts to achieve a satisfactory English level required of them to graduate. They can choose to sit for TOEIC, TOEFL or IELTS to obtain an English certificate, which can prove whether they have attained the expected English proficiency level. In recent years, the Vietnamese government has encouraged tertiary institutions to teach major subjects in English in advanced programs. Van Van (2010) mentioned that one of the most challenging issues in 
Vietnamese higher education lies in the English teaching contents. It is because, unlike general education, where the teaching contents, as well as training and educational goals, are consistently imposed by the Government, the question is of how the English curriculum is designed in the hands of each institution.

Despite the introduction of the Communicative Language Teaching method since the beginning of the 2000s, most of the language programs in junior high schools in Vietnam focus on grammar and vocabulary and explicit grammar teaching is the most popular because the primary mission centres on helping students pass the exam. Most Vietnamese students learn English officially from Grade 6 to Grade 12 and then take an English university entrance exam, which includes only three parts: grammar, vocabulary, and reading. Only when students further their studies at university for those who choose English to be their major, will they have more chances to study and practice speaking in class. Nevertheless, most of them tend to struggle in the first semester with their English. Although most Vietnamese students spent seven years studying English during their secondary education, their English entrance exam scores are very low. For example, the average English test score at the national level in 2016 was 3.5 over 10 (Duong, 2017). This could be explained by the fact that most Vietnamese students lack learning strategies when they learn English.

In Vietnam, the issue of learning styles and strategies is not widely and duly realised. Some widely known assumptions have been made about Vietnamese learners, i.e. they are passive and group- oriented learners and they tend to learn by rote and memorising knowledge. In fact, there has been little research on Vietnamese learning styles and, if any, there is no research carried out from the students' perspectives, asking students to reflect on their learning styles and learning strategies via semi-structured interviews rather than via a questionnaire. If teachers know the answer to the above-stated questions, they will be better equipped to understand their students' needs, and to know how to help them improve and tackle the problem of second language learning. They will also be able to adapt their teaching styles to match their students' learning styles. For this myth to be unraveled, I have conducted this pilot study.

This study uses a semi-structured interview to explore learning-styles and learning strategies among first-year non-English collegiate Vietnamese students and examine the following research questions:

(1) What are the roots of the assumed styles and strategies (i.e. passive, cooperative and rote learners) among Vietnamese learners?

(2) What is the genuine picture of Vietnamese learners' learning styles and learning strategies?

\section{Literature Review}

\subsection{Research on Asian Learning Styles and Learning Strategies}

There has been a lot of research into Asian students' learning styles and strategies both in those Asian countries themselves and "alien" countries where Asian students study. Overall, learners in each Asian country will expose different tendencies toward particular styles. For example, Chinese, Korean and Indonesian students choose auditory learning as their major learning style while Thai, Malay and Japanese students as minor learning style (Saracho, 1997, p. 18). Although not all Asian learners have similar learning styles, a few assumptions can be found.

Firstly, Asian learners tend to be more cooperative (Scarcella, 1990, p. 123). However, it is in doubt whether this learning style is culturally or contextually affected. It could be because some Asian countries such as China, Japan, Korea, Singapore, and Vietnam are influenced by Confucian heritage culture and ideologies, so they share some characteristics of a collectivist society. Nevertheless, cultural factors may not be the only determinant to account for the use of a specific learning style as individual personality traits may explain the presence of such a style (Ibrahimoglu, Unaldi, Samancioglu, \& Baglibel, 2013). In this sense, not all Asian learners are cooperative or prefer cooperative learning. A study conducted by Park (2002) on 857 high school students of mixed originality in the United States concluded that Vietnamese, Mexican and Hmong leaners preferred group learning while Armenian and Korean students did not. Besides, some studies have shown that Asian learners who studied English for more than three years in the States tend to favor group learning less than those who spent short periods studying English there (Reid, 1987, pp. 95-96).

Another learning style is passive learning. It is thought that Asian learners are inclined to adopt passive learning styles because they tend to keep quiet in the classroom. Also, people have preconceptions that Asian learners really want to listen and obey. However, according to some research, students do not want to adopt that role, i.e. obedient listeners in class. They "do not want to sit in class passively receiving knowledge [but] want to explore the knowledge themselves" (Littlewood, 2000, pp.33-34). Furthermore, it is claimed that those who support those prejudiced ideas do not take into account the cultural factors, cultural clashes and students' expectations (Chalmers \& Volet, 1997, pp. 90-91). This is to say that these students are not passive in thinking and that they have different views about the suitability of speaking out in classroom. 
Asian learners tend to resort to rote learning strategy, or surface approach, which means learning something via repetition so that knowledge can be repeated from memory (Watkins \& Biggs, 1996). This learning approach contrasts with deep learning approach, which is a combination of understanding and memorising (Marton, 1996). Many people have that assumption because Asian learners spend a great deal of time memorizing. However, some research indicates that they understand better through memorisation (Marton, 1996) and "rely less on rote learning to simply reproduce information" (Chalmers \& Volet, 1997, p. 90).

\subsection{Research on Vietnamese Learning Styles and Learning Strategies}

As a member of the Asian continent, Vietnam, to some extent, has its culture akin to that of other countries in the region and similar statements were made to describe Vietnamese students' learning styles and strategies. It is noticeable that regarding history, Vietnam was dominated by the Chinese for nearly one thousand years. Vietnamese people value harmony, family, achievement and hierarchy (Triandis, 1995) because China's Confucian ideologies are deeply ingrained in Vietnamese culture, which focuses on virtue, respect, obedience and the relationship between ruler and subject, father and son, older brother and younger brother, husband and wife, seniors and juniors (Doan, 2005; Nguyen, Terlouw, \& Pilot, 2005).

In Vietnamese culture, self-respect and respectful attitudes are very important. This is expressed through politeness and obedience. Besides, Vietnamese people tend not to reveal their feelings and avoid conflict for fear that they will hurt others' feelings. Thus, in the classroom, Vietnamese students tend to keep quiet and instead of volunteering, they wait until they are called on to answer the question posed by their teacher. They even also avoid eye contact with the teacher and tend to copy down everything on the board. This is due to the belief that being quiet in class means showing respect towards the teacher and they do not raise questions because they may think it is enough to receive knowledge transferred from their teachers (Huong, 2008). However, this behaviour is often "misunderstood as a passive or non-cooperative attitude" (Nguyen, 2002). However, Truong (2017) states that Vietnamese students are not passive at all and the reasons why they appear passive are related to their shyness and face-saving attitudes.

Furthermore, in line with the common stereotypes of Asian learners, Vietnamese learners employ more frequently "repetitive learning strategies" (Helmke \& Tuyet, 1999), but "repetition appears to have a different psychological meaning" (Helmke \& Tuyet, 1999) for them. This is to say that the stereotype of being rote learners is not applied to Vietnamese learners. Nevertheless, more research is needed to understand Vietnamese students with a full understanding of Vietnamese culture and appropriate interpretation of the learning strategies commonly used by Vietnamese students. Since the introduction of Communicative Language Teaching (CLT) method to Vietnam in the 1990s, the learning and teaching practice has changed to a certain extent. Departing from the traditional way of learning, students are relatively more active thanks to classroom communicative activities. Nevertheless, from my teaching and learning experience, teachers sometimes complain that some of their students remain quiet although they try to encourage them to talk and put them in a group so that they will feel more secure. It can be partly because of the students' personality or of the fact that they are still influenced by how they were used to be taught. Therefore, to better understand those assumptions, teachers should conduct a study in their teaching context though there has been little research on Vietnamese learning styles and strategies.

\section{Methodology}

\subsection{Setting}

The educational institution that I am affiliated with is Van Lang University, Faculty of Foreign Languages in Vietnam where I have been working as a full-time English lecturer for eight years. I have been away from my teaching for five months because I am currently enrolled in a PhD program in TESOL at University Putra Malaysia. Last semester, I was in charge of teaching first-year non-English major students (e.g. students of Computer Science, Architecture, Engineering and Biotechnology) in Vietnam and the participants who volunteered to take part in this pilot study were my students. As mentioned in the literature, although students spend many years learning English during their secondary education, most of the non-English major students still struggle with their English during the first year at university and for most of those students, their English is at an elementary level. Since their focused subjects at high school to pass the university entrance exam were Mathematics, Chemistry and Physics, their English was not given due attention at high school. Thus, it is stated in the policy of my university that all of the students belong to the non-English major group will be assisted to review and improve their English language from elementary level. Accordingly, one of the important missions of the English Department is to produce qualified students able to communicate with foreigners in English and develop both their proficiency and their knowledge about the socio-cultural background of English-speaking people.

\subsection{Participants}

Theconvenient sampling strategy was used to locate non-English major collegiate students at Van Lang University who were willing to share information about 
their learning English experiences as students. The participants include two first-year students from Van Lang University, i.e. a male student from the Department of Biology and a female student from the Department of Architecture who were invited to take part in this pilot study. Their mother tongue is Vietnamese and their English is at pre-intermediate level. They have spent over seven years studying English and have not taken any extra English course outside the school program. The sample was recruited through invitation posted on personal communication website with the students. Detailed demographic information for participants is shown in Table 1.

Table 1. Demographic information for the participants. F, Female, M, Male

\begin{tabular}{|c|c|c|c|c|}
\hline Name & Gender & Faculty & $\begin{array}{c}\text { Years of } \\
\text { learning } \\
\text { English }\end{array}$ & English level \\
\hline Sophie & F & Architecture & 7.5 & Pre-intermediate \\
\hline Ben & M & Biology & 10 & Pre-intermediate \\
\hline
\end{tabular}

\subsection{Data Collection Method}

The two students completed the background questionnaires which are intended to elicit demographic background information such as sex, age, and self-rated English proficiency. Face-to-face virtual interviews between the researcher and the students via Skype were recorded, with the permission of the students being interviewed. Interviews were conducted in English. Each participant was interviewed for about 30 minutes or more, depending on the course of the conversation. The interview was mostly based on an open-ended format, allowing the interviewees to control the content in response to questioning.

Questions raised were intended to uncover whether Vietnamese students are passive, group-oriented learners, who use rote learning as the principal strategy or not. Besides general questioning, strategy-related questions, based on Wang \& Bai's (2017) validated Questionnaire of Self-Regulated Learning Strategies were employed to find out if Vietnamese college students use any other strategies. Gathered data from each interview was organized and transcribed, including details on dates, pseudonyms, and any other notes that were taken during and after the interviews. Although the researcher had some pre-determined interview questions, she allowed for the conversation to emerge naturally and asked follow-up questions when appropriate. After the interviews, the recordings were transcribed into computer files with the students' names replaced by two pseudonyms, i.e. Sophie and Ben.

\subsection{Data Analysis Method}

The conversation transcripts were read by the researcher and used grounded theory approach to data analysis. The strategy is to identify themes and make a detailed inspection of tape recordings and transcriptions of participants' responses during interviews to find out their learning styles and learning strategies.

\subsection{Transcribing}

The audiotaped data were transcribed in as much detail as possible. No attempt was made to temper the transcripts, for instance, by excluding incomplete utterances or restoring what was said into grammatical form. However, the transcripts do not include detailed descriptions of supra-segmental features (e.g. intonation, rhythm and prosody) or body movements (e.g. gaze and gesture) because their inclusion in the transcripts and their analysis were beyond the scope of this study. The database consists of 28 semi-structured questions.

\subsection{Coding}

Coding categories were made based on the research questions. There were nine codes emerging from the data: passive, active, rote-learning, cooperative learning, individual learning, autonomous learning, memorising and understanding, indirect strategies, direct strategies. The researcher first started with a start list for deductive coding (Miles, Huberman, \& Saldana, 2014) based on this study's interview protocol. The researcher then searched for broad categories and then developed themes that emerged from the participants' experiences, which were labelled by identifying phrases that related to our themes. After concluding the first cycle coding, the researcher moved on to second cycle coding as a way to refine themes. The researcher organized the first cycle codes by clustering them under common themes or patterns that emerged from the interviews. The researcher conducted second cycle coding, which included rearranging and reorganizing the codes. The researcher continuously refined and reworked the pattern codes until the researcher felt the final codes were representative of the participants' experiences. It was through this process that the findings related to this current study emerged.

\subsection{Trustworthiness and Reliability}

I have been able to collect rich data and a thick description, which has increased the trustworthiness of the data collected (Glesne, 2015). My findings are based on the raw data that was collected and the exact quotes from my study participants. I employed reliability procedures (Creswell, 2007), including conducting multiple reviews of transcripts to reduce mistakes in participants' narratives of their experiences. Finally, I conferred with an international higher education scholar regarding my study topic, the nature of our study, and the process by which I collected 
my data. We have also shared my preliminary findings with my peers proficient in qualitative research, and as a result, I was able to confirm that my 'tentative interpretations' (Merriam \& Grenier, 2002, p. 31) were appropriate and congruent with the themes that I identified from my findings.

\subsection{Researcher Reflexivity}

Reliability often lies within the researcher who is the primary instrument for data collection; thus, my positionality was used as a form of reliability (Merriam \& Tisdell, 2015). As the researcher, I was aware that reflexivity affected how I made meaning of participants' worldviews. As the author, I identified myself as an EFL (English as a Foreign Language) lecturer whose primary language is Vietnamese and second language is English. I have been teaching English in Vietnam for eight years, and I recognised the privileges and benefits of my Vietnamese citizenship when conducting this mini research project. My position as a full-time English lecturer at Van Lang University provided access and acceptance by my participants and the research site. I benefitted from the outsider status as an Asian scholar, and at the same time, also benefitted as an insider who had prior experience in Vietnam. Very few challenges or tense moments arose in the researcher and participant interactions, as all participants were vocal about their admiration for my teaching experience and its education institutions which definitely benefitted me as the first author. The only barrier at times would be related to language, as participants would sometimes struggle to choose the correct wording and/or phrasing to represent their experiences. These situations were mediated by the researcher recalling all of her qualitative interview training and holding back her natural inclination to provide or correct words for the participants.

\section{Results and Discussion}

\subsection{Results}

A summary of findings and discussion based on the interviews with the two students is given. In some places, verbatim quotes are taken from the transcripts while in other places, comments and interpretations based on the interviews are offered to provide a a readable narrative about their features of learning. Six major issues emerged.

\subsection{Passive Learners or Active Learners}

Generally speaking, Ben exudes a clear aura of confidence and being an active learner because he raises his hand "most of the time" in class, except when the posed questions are very easy. Moreover, whenever his teacher raises a question, his mind is always active since he said: "I will think about it and most of the time, I raise my hand to let my teacher know my answer". Also, though believing what the teacher says, Ben affirmed that he would usually challenge his teacher with difficult questions and ask him or her if he does not comprehend or doubt any point in the lesson. Surprisingly, it is contrary to the deeply-held belief that students should not challenge their teachers if they are to be polite.

Meanwhile, Sophie seems to be passive in the classroom because she "rarely" volunteers to answer the questions; but is she truly a passive learner? Although she does not like raising her hand in class, she does consider her teachers' questions:

I try to find out the answer and keep it there in my head. I don't raise my hands or shout out the answer like my friends. I will wait for my teacher to give the answer and then I compare my answer with hers to see if I am correct.

Not raising hands does not mean that Sophie is a passive learner because her mind is active and she's not afraid of making mistakes. Besides, she does challenge her teacher sometimes with difficult questions although it depends on how her teacher is. In fact, she discloses that she prefers "listening to others more than speaking [her] ideas".

\subsection{Group Learning or Individual Learning}

Unlike Ben, who enjoys working in groups, seeing the positive sides of completing work with his friends, i.e. to learn many things from friends and save time, Sophie prefers working alone. This is not to say that Sophie is reserved or reticent because she may have an unpleasant experience from working in a disorganised group where opinions differ:

I prefer working alone because I feel tired when working in groups. Sometimes, everyone doesn't agree with each other and does what he or she likes and they are sometimes not on time for group meetings.

\subsection{Autonomous Learning}

To the two freshmen's minds, knowledge is not always something that is transferred directly from their teacher. It is evidenced by their independent learning outside the classroom. When they query and the answer are given by their teacher, they will google it. Ben says: "I will figure out the answer myself and I will check the information on the internet when I go home" and Sophie, "I will check the answer on Google". Moreover, on being questioned about their choice between the the deductive and inductive way of learning grammar, Sophie chooses the second way and adds that she likes discovering things herself

\subsection{Rote-Learning (Surface Approach) or Memorizing and Understanding (Deep Approach)}

Both Ben and Sophie have the same opinions in that they hate rote learning and it is very tiring and boring to learn by 
heart. While Ben admits that he only remembers the lesson after his teacher explains it and he does exercises to practice, Sophie prefers learning visually: "I like learning through pictures and something that interests me". For example, when being asked how to memorise vocabulary, Sophie gives a surprising answer that she does not record any new words in her book but still remembers them exactly:

In class, my teacher usually writes the new words on the board or presents them in powerpoint and I look at them, and I remember them. I don't know how I can remember them, but when I finish the lesson, I take the bus to go home and on the bus, the new vocabularies appear in my mind.

On the contrary, Ben is more organised; he writes down new vocabulary in a notebook together with not only their meanings but also illustrating examples so that it will be easier for him to review later. However, have they ever resorted to rote learning? Interestingly, both of them agree that they will not take risks at the expense of their scores. It means that they do not refuse to learn by heart for the exam even though they do not comprehend.

\subsection{Indirect Strategies: Metacognitive, Affective and Social}

Regarding metacognitive strategies, both students employ organisational skills when listening. They clarify the objectives of the listening task. Specifically, before listening, they read the questions carefully first. Nevertheless, this organisational skill is more clearly seen in the way Ben learns vocabulary because he records new words in a notebook for later review.

Additionally, both Sophie and Ben know how to evaluate their progress in listening. Ben says "I compare it with my listening performance many months ago" while Sophie has a different way to know how much better her listening is:

Well, I usually practice listening on the Internet. There is a very good website like Randall lab and there are many different levels for you to choose. When I choose the upper intermediate level more than the level I think I am at and I can listen about $70 \%$, I am very happy because I think I am making progress.

Concerning affective strategies, while Sophie can maintain a positive attitude toward difficult questions, Ben feels angry. However, he knows how to build positive emotion again. He says: "I will stop thinking about the task and I listen to music or watch TV or go to sleep and I will complete it after that."

Regarding socio-interactional strategies, both pose questions whenever they cannot find out the answers themselves. In addition, when watching films, Sophie wonders a lot about some social behaviours or sayings by which she is bewildered and searches for them online later: "I tend to wonder a lot about things, and I usually go online and find out the information."

\subsection{Direct Strategies: Cognitive Strategies}

On approaching a difficult question in a listening or reading task, both utilise guessing and inferring techniques, matching the information against their own experience. Ben says: "I will guess the answer from what I know through books or real life". Likewise, Sophie states: "I tend to make a guess and try to finish all the answers", adding that "if a familiar topic talks about something strange or different, I usually compare it with what I know". Furthermore, that Ben and Sophie can identify main ideas from the detail ideas to understand what a reading passage talks about indicates that they know how to synthesise information. Finally, when copying down a new vocabulary item, Ben also marks the stressed syllable on it, which means that he analyses what he studies, i.e. break a multi-syllabic word into parts.

\section{Discussion}

Discussing emerging issues will involve collaborating and contrasting findings on learning styles and learning strategies among both Asian and Vietnamese learners. Contrary to what is stated about Vietnamese learners (Doan, 2005; Nguyen, 2002), the two participants' responses reveal that they are not passive learners at all. Even when they do not raise their hands in class or think their ideas out loud, their minds are also active because they still think about the response to their teacher's questions and try to figure out the answers and when they do not comprehend something, they will ask their teacher. That they do not appear to be active is partly due to their learning styles or partly because questions are easy.

Moreover, the findings show a sharp contrast to the widely- held belief about the reason why Vietnamese learners are passive (Doan, 2005; Nguyen, 2005), i.e., they want to be polite to teachers, and they see knowledge as something their teachers transfer to them. From the findings, it is clear that respecting the teacher does not mean they cannot challenge them and that the students are very autonomous. Furthermore, whether Vietnamese students are group-oriented or not is not proven from the findings. It may also depend on the students' personality and how they view learning in a group. For that reason, further research is necessary. As regards learning strategies, it is not always the rote learning approach that the students employ. They only resort to it for fear of having lower marks in the exam. In fact, they learn with understanding and employ other strategies to help them memorise the knowledge.

\subsection{Teaching Implications}

Concerning learning styles:

Though there is evidence suggesting that "culture, as 
learned by the child from family, community, and school, has a strong influence on learning style" (Hedge, 2001, p. $19)$ and that a child's learning style depends on the "type of society, and the way [he] is reared" (Brown, 2000, p. 115), teachers should avoid stereotyping. It is because even in the same culture, there is still a wide variety and there are serious and unfathomable dangers if teachers misidentify learning styles. If that was the case, the teacher might provide wrong instructional practices, which can lead to students' academic failure.

Moreover, though learning styles appear stable, they are changeable; otherwise students will not be able to surpass drawbacks or restraints of their own style. In fact, they will exert a certain style appropriate to the context. Being informed of learners' own styles can be a great boon to teachers. However, not many learners can identify their own styles. For those learners, teachers should provide them with opportunities to discover their styles through letting them face certain challenging tasks and encouraging them to experience themselves in different learning styles since students who employ multiple learning styles can enjoy "greater classroom success" (Reid, 1987, p. 101).

Finally, no style should be favored more than others. They are equally important. Therefore, teachers need to be lenient with some types of learners. For instance, they should be more patient with reflective learners who need more time to consider their responses and more tolerant of errors made by impulsive learners. Furthermore, teachers should be aware of the importance of learning styles because if teachers consider styles, they can "help improve both instruction and assessment [and] can show sensitivity to cultural and individual diversity that is so often absent in the classroom" (Zhang \& Sternberg, 2001, p. VIII)

\subsection{Concerning Learning Strategies}

Since the Cognitive Approach was introduced in 1970, language learners were thought to be "more actively responsible for their own learning" (Larsen-Freeman, 2000, p. 159). Therefore, they themselves try to employ possible techniques to achieve second language learning success. Recognising and understanding those strategies, teachers can realise what makes learners successful so that they can set up a favourable classroom setting to facilitate their students and choose suitable activities for different learners. However, it is still not sufficient because not all learners are good learners; therefore, they "need training in learning strategies" (Larsen- Freeman, 2000, p. 159). To realise this, teachers should make students "aware of their own style preferences and the strategies that are derived from those styles" (Thompson \& Rubin, as cited in Brown, 2000, p. 131). This can be done through interviews, checklists, tests or techniques.

Moreover, teachers can "embed strategy awareness and practice into their pedagogy" (Ellis, as cited in Brown, 2000 , p. 131). In other words, learner strategies can be practiced through language lessons such as communicative or error recognition exercises or games. Finally, learners should be provided with textbooks including strategies (O'Malley \& Kupper, as cited in Brown, 2000, p. 131). However, it does not mean that learners' success can be ensured because learner training usually takes a long time and we are not certain whether learners will be able to apply learning strategies effectively due to external factors such as religion, culture, previous learning experience or independent learning outside the classroom which can contribute to learning success. Hence, what teachers can do is to offer learners a great diversity of strategies so that they will opt for the ones that suit their learning styles as well as help them know what, when and how of employing appropriate learning approaches.

Given that certain learning strategies are attributed to external factors such as personality, language proficiency, and culture, further research is necessary to discover the significance of that associated relationship. This will not only help researchers see how each of these factors is related to learning strategies but also enable teachers to consider appropriate factors in learner training.

No matter in what ways strategies are used, teachers should also pay attention to the conditions that determine the usefulness of a strategy. In other words, a helpful strategy must fulfill the following three conditions: relating to available L2 task, fitting a particular student's learning style preference, being employed effectively in conjunction with other relevant strategies (Oxford, 1990, p. 8). Also, teachers should look at what good learners do to acquire knowledge so that they can help other learners to better their language learning. For example, good learners tend to make and try out guesses and have a strong desire to communicate and will do many things to make their ideas understood. Furthermore, it should be noted that an important aim for most curricula is self-regulation by learners (Zimmerman \& Schunk, 2012) and developing confidence and independent-thinking in learners in school is important for both schools and society as well.

\section{Conclusions}

To sum up, this exploratory study is set out to pave the way for future research that is intended to discover Vietnamese students' learning styles and strategies. The interviews with the two students mentioned above reveal that Vietnamese students are not passive and not rote learners at all. Although there are no fixed styles and strategies, it is worth the effort to increase learners' awareness of their styles and strategies because "the burden on the learner is to invoke the appropriate style for the context, and the burden on the teacher is to understand the preferred styles of each learner and to sow the seeds for flexibility" (Brown, 2000, p. 118). Besides, the biggest challenge for the teachers is to find ways to promote 
learners' autonomy according to their background and their characteristics. Therefore, teachers should also make appropriate judgments about individual learners and provide them with optimal opportunities for learning. It is also interesting to investigate if there is any distinction between each gender's learning styles and learning strategies regarding such factors as age, gender, major and personality. Therefore, future research should look into those factors and include students with those variants into the qualitative study.

\section{Appendix}

\section{Transcript of Interviews}

Sophie

Researcher: Hi, Sophie. How are you?

Sophie: Hi Miss, I am fine and you?

Researcher: Very well, thanks Sophie. As I explained to you the purpose of today's interview yesterday. So, now we are meeting online to record my interview with you about your English learning experience. So are you ready, Sophie?

Sophie: Yes, Miss. I am very happy to share.

Researcher: Ok, Sophie, the first question is, can you tell me how often you raise your hands in class?

Sophie: Um, I think sometimes. But I don't like raising hands

Researcher: Can you tell me why?

Sophie: Well, I like listening to others than speaking my ideas.

Researcher: If you don't understand something, what will you do?

Sophie: I will ask my teacher

Researcher:When your teacher raises a question, if you are not sure of the answer, but really want others know what you think, will you raise your hand?

Sophie: I think I will.

Researcher: When your teacher poses a question in front of the class, what will you do?

Sophie: I try to find out the answer and keep it there in my head. I don't raise my hands or shout out the answer like my friends. I will wait for my teacher to give the answer and then I compare mine with hers to see if I am correct

Researcher: Are you afraid of making mistakes or giving incorrect answers?

Sophie: No

Researcher: Do you believe in what your teacher says?

Sophie: Of course, yes

Researcher: If you think that your teacher's answer may not be correct, what will you do?

Sophie: I will ask her again and I will check that answer on Google

Researcher: Do you challenge your teacher by asking him or her difficult questions?

Sophie: Yes, but it depends on each teacher. If my teacher is easy-going, I will ask her.

Researcher: When you encounter a difficult task, how will you feel?

Sophie: I feel ok and I will try my best to solve it

Researcher: How often do you give comments to your friends' postings on forums on the blackboard or their group presentations?

Sophie: Rarely

Researcher: Do you like working in groups or alone?

Sophie: I prefer working alone because I feel tired when working in groups. Sometimes, everyone doesn't agree with each other and does what he or she likes and they are sometimes not on time for group meetings.

Researcher: Do you like learning English in a funny way, let's say learning English with games?

Sophie: I don't think so. I like learning in a serious classroom setting

Researcher: Do you tend to learn lessons by heart, Sophie?

Sophie: No, I hate learning by heart. I like learning through pictures and something that interests me.

Researcher: But, supposing you don't understand the lessons but your teacher asks you to review them for the exam, will you do what he or she tells?

Sophie: Certainly yes, because I don't want to have lower marks

Researcher: When you watch films, there are some social behaviors and sayings that you don't understand, what will you do?

Sophie: I tend to wonder a lot about things, and I usually go online and find out the information

Researcher: When you are given a listening task, let's say you have to listen to a conversation between Mary and Peter, and then you have to answer several multiple choice questions, can you tell me the steps that you complete the task?

Sophie: I will read the questions first and then I listen and answer the questions.

Researcher: Do you take notes or write down key words when you are listening?

Sophie: No. I remember what I have to listen for and try to find the answer in what I listen.

Researcher: Do you imagine the conversation in your head or predict the answers from your own experience before you listen?

Sophie: Generally, I don't. I just remember what I have to listen for.

Researcher: How do you know that you are making progress in your listening skill?

Sophie: Well, I usually practice listening on the Internet. There is a very good website like randall lab and there are many different levels for you to choose. When I choose the upper intermediate level more than the level I think I am at and I can listen about 70\%, I am very happy because I think 
I am making progress.

Researcher: When you cannot understand some details or a word in the listening recording, what will you do?

Sophie: I tend to make a guess and try to finish all the answers

Researcher: Now, can you tell me the steps that you finish a reading task?

Sophie: First, I will read the questions, and then I read the passage.

Researcher: How do you distinguish main ideas from detailed ideas of a paragraph?

Sophie: The main idea is usually at the beginning of the paragraph.

Researcher: If the content of the reading is about a familiar topic, let's say going shopping, do you connect or infer from what you already know with what you are reading?

Sophie: Sure. If a familiar topic talks about something strange or different, I usually compare it with what I know.

Researcher: Ok, do you usually read the text again at home?

Sophie: No, unless it is for the exam.

Researcher: Ok, now can you tell me how you memorize the vocabulary that is taught in class?

Sophie: In class, my teacher usually writes the new words on the board or presents them in power point and I look at them and I remember them

Researcher: So, you don't take notes or write new words in your notebook?

Sophie: No, I don't write any words in my notebook

Researcher: But, how can you remember all of the new words and their meanings if there are about 20 new words in a lesson?

Sophie: I don't know how I can remember them but when I finish the lesson, I take the bus to go home and on the bus, the new vocabularies appear in my mind.

Researcher: So, how about studying grammar, do you like your teacher telling you a grammar rule and then you do the exercises or you want to figure out the rule yourself?

Sophie: I like discovering things myself, so I like the second choice more

Ben

Researcher: Hi, Ben. How are you?

Sophie: I am fine, Miss. Thanks Miss. How about you?

Researcher: Very well, thanks Ben. As I explained to you yesterday the purpose of today's interview, so, now we are meeting online to record my interview with you about your English learning experience. So are you ready, Ben?

Researcher: OK, so , the first question is, in class, when your teacher raises a question, what will you usually do?

Ben: I will think about it and most of the time, I raise my hand to let my teacher know my answer.

Researcher: If you don't understand something, what will you do, Ben?

Ben: I will figure it out myself first and then if I still can't understand, I will ask my teacher

Researcher: Do you believe in what your teacher says?

Ben: Absolutely

Researcher: Do you usually ask your teacher difficult questions?

Ben: yes, of course

Researcher: So, when you doubt something that your teacher says, do you argue?

Ben: Well, I will tell my teacher what I think and then I will check the information on the internet when I go home

Researcher: Are you afraid of making mistakes, for example, a grammar mistake?

Ben: Before I was, but not now

Researcher: Can you tell me why, Ben?

Ben: Yes. When I got the answer, but others didn't, my teacher praised me and I felt very happy.

So, I usually raise my hand in class.

Researcher: When your friends make a presentation or post something onto the forum, how often do you give comments?

Ben: Most of the time, I will tell them what I think

Researcher: Now, can you tell me how you remember a grammar rule?

Ben: My teacher explains it and I do exercises to practice that rule and then I will remember it

Researcher: Do you like learning by heart?

Ben: No, I don't. I think it is very boring to learn by heart and I will feel very tired. I only remember when I understand

Researcher: But when your teacher asks you to review the lessons that you don't understand for the exam, will you follow what she or he tells?

Ben: Absolutely, yes, because I don't want to have lower marks

Researcher: How do you expect the English classroom atmosphere should be?

Ben: Well, I want the classroom to be funny. I like games and I don't like sitting at a place and listening. I like guessing for the games.

Researcher: Ok, now another question for you is that do you like working in groups or alone? And why?

Ben: I like working in groups because I can learn many things from my friends. Besides, working in group can save time and when I am not sure about something, I can discuss with my friends.

Researcher: When you encounter a difficult task, for example, a writing task, how will you feel?

Ben: I will feel very angry.

Researcher: Will you do something to calm you?

Ben: I will stop thinking about the task and I listen to music or watch TV or go to sleep and I will complete it after that.

Researcher: When your teacher asks you a very easy question, will you raise your hand?

Ben: Generally, no, I like my teacher asking me difficult questions. 
Researcher: When you are given a listening task, asking you to answer multiple choice questions about the conversation between two people, what will be the steps for you to complete the task?

Ben: I will read the questions first and then I will listen and answer the questions

Researcher: Do you take notes when you are listening?

Ben: No, I usually close my eyes when I listen.

Researcher: Do you predict the answer before you listen?

Ben: Usually, not, I just read the questions and I remember what I have to listen for.

Researcher: If the topic of the conversation is familiar to you, but you cannot find the answer to a question, what will you do?

Ben: I will guess the answer from what I know through books or real life

Researcher: Do you think that you are making progress in your listening?

Ben: Yes, I feel better now

Researcher: How do you know that you are making progress in your listening performance?

Ben: I compare with my listening performance many months ago.

Researcher: When you are given a reading task, can you tell me how you finish it?

Ben: I will read the main ideas first to understand what the passage is about and then I read the questions and try to find the answer

Researcher: Do you read the passage again at home?

Ben: If the passage interests me, I will read it again

Researcher: Ok, now, for vocabulary learning, how do you memorize vocabulary that is taught in class?

Ben: I write new words in a notebook together with their meanings and example sentences so that I can review them whenever I want

Researcher: Do you make notes how to pronounce a new word?

Ben: I don't write the transcription like in the dictionary. I just put a mark on the stressed syllable

Researcher: How do you like studying grammar? Do you like being presented a grammar point and then doing exercises or you like the teacher letting you discover the rules yourself?

Ben: I prefer my teacher presenting it and we will do exercise to practice.

\section{REFERENCES}

[1] Bialystok, E., \& Fröhlich, M. (1978). Variables of classroom achievement in second language learning. The modern language journal, 62(7), 327-336.

[2] Brown, H. D. (2000). Principles of language learning and teaching. New York: Addison Wesley Longman, Inc.
[3] Chalmers, D., \& Volet, S. (1997). Common misconceptions about students from South - East Asia studying in Australia. Higher Education Research \& Development, 16(1), 87-99.

[4] Creswell, J. W. (2007). Qualitative inquiry and research design: Choosing among five approaches

[5] Curry, L., \& Adams, C. (1991). Patterns of learning style across selected medical specialties. Educational Psychology, 11(3-4), 247-277.

[6] Denham, P. (1992). English in Vietnam. World Englishes, 11(1), 61-69.

[7] Doan, D. H. (2005). Moral education or political education in the Vietnamese educational system? Journal of Moral Education, 34(4), 451-463.

[8] Duong, T. (2017). Can you get $10 / 10$ on Vietnam's English high school exam? . from https://e.vnexpress.net/news/new s/can-you-get-10-10-on-vietnam-s-english-high-school-exa m-3612288.html

[9] Giang, K., Thi, B., \& Tuan, V. V. (2018). Language Learning Strategies of Vietnamese EFL Freshmen. Arab World English Journal (AWEJ) Volume, 9.

[10] Glesne, C. (2015). Becoming qualitative researchers: An introduction: Pearson.

[11] Hedge, T. (2001). Teaching and learning in the language classroom (Vol. 106): Oxford University Press Oxford, UK.

[12] Helmke, A., \& Tuyet, V. T. A. (1999). Do Asian and Western students learn in different way? An empirical study on motivation, study time, and learning strategies of German and Vietnamese university students. Asia Pacific Journal of Education, 19(2), 30-44.

[13] Hong-Nam, K., \& Leavell, A. G. (2006). Language learning strategy use of ESL students in an intensive English learning context. System, 34(3), 399-415.

[14] Huong, P. T. T. (2008). How Vietnamese Culture Influence on Learning and Teaching English. Online Submission.

[15] IIbrahimoglu, N., Unaldi, I., Samancioglu, M., \& Baglibel, M. (2013). The relationship between personality traits and learning styles: a cluster analysis. Asian Journal of Management Sciences and Education, 2(3), 93-108.

[16] Kachru, B. B. (1990). World Englishes and applied linguistics. World Englishes, 9(1), 3-20.

[17] Larsen-Freeman, D. (2000). Techniques and principles in language teaching: Oxford University.

[18] Littlewood, W. (2000). Do Asian students really want to listen and obey? ELT journal, 54(1), 31-36.

[19] Marton, F. (1996). Memorizing and understanding: The keys to the paradox? The Chinese learner: Cultural, psychological and contextual infiuences, 69-83.

[20] Merriam, S. B., \& Grenier, R. S. (2002). Qualitative research in practice: Examples for discussion and analysis: Jossey-Bass.

[21] Merriam, S. B., \& Tisdell, E. J. (2015). Qualitative research: A guide to design and implementation: John Wiley \& Sons. 
[22] Messick, S. (1976). Personality consistencies in cognition and creativity. Individuality in learning, 4, 22.

[23] Miles, M. B., Huberman, A. M., \& Saldana, J. (2014). Qualitative data analysis: A methods sourcebook. 3rd: Thousand Oaks, CA: Sage.

[24] Mortimore, T. (2008). Dyslexia and learning style: a practitioner's handbook: John Wiley \& Sons.

[25] Nguyen, Terlouw, C., \& Pilot, A. (2005). Cooperative learning vs Confucian heritage culture's collectivism: confrontation to reveal some cultural conflicts and mismatch. Asia Europe Journal, 3(3), 403-419.

[26] Nguyen, T. H. (2002). Vietnam: Cultural background for ESL/EFL teachers. The Review of Vietnamese Studies, 2(1), 1-6.

[27] Nunan, D. (1999). Second Language Teaching \& Learning: ERIC.

[28] Oxford, R. (1990). Language learning strategies (Vol. 210): New York: Newbury House.

[29] Park, C. C. (1997). Learning style preferences of Asian American (Chinese, Filipino, Korean, and Vietnamese) students in secondary schools. Equity and Excellence in Education, 30(2), 68-77.

[30] Park, C. C. (2002). Crosscultural differences in learning styles of secondary English learners. Bilingual Research Journal, 26(2), 443-459.

[31] Reid, G. (2007). Motivating learners in the classroom: Ideas and strategies: Sage.

[32] Reid, J. M. (1987). The learning style preferences of ESL students. TESOL quarterly, 21(1), 87-111.

[33] Renzulli, J. S., \& Dai, D. Y. (2001). Abilities, interests, and styles as aptitudes for learning: A person-situation interaction perspective. Perspectives on thinking, learning, and cognitive styles, 23-46.

[34] Rubin, J. (1975). What the" good language learner" can teach us. TESOL quarterly, 41-51.

[35] Saracho, O. N. (1997). Teachers' and Students' Cognitive Styles in Early Childhood Education: ERIC.

[36] Scarcella, R. C. (1990). Teaching language minority students in the multicultural classroom: Prentice Hall.

[37] Scarcella, R. C., \& Oxford, R. L. (1992). The tapestry of language learning: The individual in the communicative classroom: Heinle \& Heinle Boston, MA.

[38] Sternberg, R. J. (1995). Styles of thinking and learning. Language Testing, 12(3), 265-291.

[39] Triandis, H. C. (1995). Motivation and achievement in collectivist and individualist cultures. Advances in motivation and achievement, 9, 1-30.

[40] Trương Thị Như, N. (2017). Understanding first year university students' passivity via their attitudes and language behaviors towards answering questions in class.

[41] Van Van, H. (2010). The current situation and issues of the teaching of English in Vietnam. 立命館言語 文化研究, 22(1).
[42] Wang, C., \& Bai, B. (2017). Validating the Instruments to Measure ESL/EFL Learners' Self - Efficacy Beliefs and Self - Regulated Learning Strategies. TESOL quarterly, 51(4), 931-947.

[43] Watkins, D. A., \& Biggs, J. B. (1996). The Chinese learner: Cultural, psychological, and contextual influences. Comparative Education Research Centre, Faculty of Education, University of Hong Kong, Pokfulam Road, Hong Kong; The Australian Council for Educational Research, Ltd., 19 Prospect Hill Road, Camberwell, Melbourne, Victoria 3124, Australia..

[44] Young, B. (2018). International Students' Use of English Language-Learning Strategies at a Private High School.

[45] Zhang, L.-F., \& Sternberg, R. J. (2001). Thinking styles across cultures: Their relationships with student learning. Perspectives on thinking, learning, and cognitive styles, 197-226.

[46] Zimmerman, B. J., \& Schunk, D. H. (2012). Self-regulated learning and academic achievement: Theory, research, and practice: Springer Science \& Business Media. 